\title{
TENSÃO SUPERFICIAL NO ENSINO DA QUÍMICA: UMA PRÁTICA EXPERIMENTAL E UM JOGO DIDÁTICO COM BASE NO CICLO DA EXPERIÊNCIA KELLYANA
}

\section{SURFACE TENSION IN CHEMISTRY TEACHING: AN EXPERIMENTAL PRACTICE AND A DIDACTIC GAME BASED ON THE KELLY'S CYCLE OF EXPERIENCE}

\author{
Palloma Joyce de Aguiar Silva ${ }^{1}$; Rayanne da Silva Lima²; Flávio José de Abreu Moura ${ }^{3}$; \\ Renata Joaquina de Oliveira Barboza ${ }^{4}$; Kilma da Silva Lima Viana ${ }^{5}$
}

\begin{abstract}
RESUMO
A evasão nos cursos de licenciatura é um problema que vem sendo estudado há muito tempo, principalmente na área de química, na qual os relatos estão sempre relacionados as práticas de ensino desde o Ensino Médio, que na maioria das vezes é marcada pela abordagem Tradicional, em que os estudantes devem apenas memorizar e reproduzir conteúdos, sem nenhuma conexão com seu cotidiano, permitindo assim, um distanciamento dos estudantes e a disciplina. Outro ponto a ser considerado é realização de práticas experimentais que são importantíssimas na área de química, e que muitas vezes não são feitas por falta de espaço e materiais em laboratórios, colaborando ainda mais para o desinteresse dos estudantes para a química. De forma a dinamizar o ensino de química, o artigo tem por objetivo analisar o desenvolvimento de uma atividade experimental e um jogo didático para o conteúdo de "Tensão superficial" baseado no Ciclo da Experiência Kellyana - CEK. O trabalho é oriundo de atividades de extensão realizadas a partir do Programa Internacional Despertando Vocações para as Licenciaturas (PDVL) e para sua execução, realizamos um experimento no conteúdo de tensão superficial, utilizando como base metodológica o Ciclo da Experiência Kellyana - CEK, de George Kelly (1963), que é composto por cinco etapas: Antecipação, Investimento, Encontro, Confirmação ou desconfirmação e Revisão Construtiva. Os sujeitos da pesquisa foram 30 estudantes da primeira série do Ensino Médio da Escola de Referência Dias Cardoso, na cidade de Vitória de Santo Antão-PE. A partir do estudo, percebemos que os estudantes destacaram que o uso de experimentos e de jogos no processo de ensino e aprendizagem nas aulas de química fazem total diferença, relatando, que "aulas assim são mais dinâmicas" e "conseguimos compreender o conteúdo com mais facilidade". Assim, concluímos que a utilização de experimentos e de jogos didáticos, quando aliados ao CEK, são eficazes para a construção de conhecimentos.
\end{abstract}

Palavras-Chave: Ensino de Química, Experimentação, Jogo Didático, CEK.

\section{ABSTRACT}

Avoidance on teachers development undergraduation courses is a problem that has been studied for a long time, mainly in the area of chemistry, and the reports are always related to teaching practices since High School, which is most often marked by the Traditional approach, in which students should only memorize and reproduce content, without any connection with their daily life, allowing a distancing between the students and the discipline. Another point to consider is the realization of experimental practices that are very important in the field of chemistry, and which are often not done due to lack of space and materials in laboratories, further contributing to students' lack of interest in chemistry. In order to stimulate the chemistry teaching, this article aims to analyze the

\footnotetext{
${ }^{1}$ Licenciatura em química, IFPE-campus Vitória de Santo Antão, palloma_joyce_aguiar@hotmail.com

${ }^{2}$ Licenciatura em química, IFPE-campus Vitória de Santo Antão, rayannelima-@ hotmail.com

${ }^{3}$ Licenciatura em química, IFPE-campus Vitória de Santo Antão, flavio.jose33@ hotmail.com

${ }^{4}$ Mestranda em Educação em Ciências e Matemática (PPGECM, Universidade Federal de Pernambuco (UFPE) Centro Acadêmico do Agreste, renata_joaquina@hotmail.com

5 Doutora em Ensino de Ciências e Matemática (UFRPE), docente, Departamento de Desenvolvimento Educacional, Instituto Federal de Educação, Ciências e Matemática (IFPE), IFPE-campus Vitória de santo antão, kilma.viana@vitoria.ifpe.edu.br
} 
development of an experimental activity and a didactic game for the content of "Surface tension" based on the Kelly's Cycle of Experience - CEK. The work is deriving by extension activities carried out from the International Program Awakening Vocations for Licentiates (PDVL) and for its execution, we conducted an experiment on the surface tension content, using as a methodological basis the George Kelly's Cycle of Experience - CEK Kelly (1963), which is composed of five stages: Anticipation, Investment, Encounter, Confirmation or Disconfirmation and Constructive Revision. The research subjects were 30 students from the grade 10 at Dias Cardoso Secondary School, in the city of Vitória de Santo Antão-PE. From the study, we noticed that the students emphasized that the use of experiments and games in the teaching and learning process in chemistry classes make a total difference, reporting that "classes are more dynamic" and "we can understand the content with more facility". Thus, we conclude that the use of experiments and didactic games, when allied to the CEK, are effective for the construction of knowledge.

Keywords: Chemistry Teaching, Experimentation, Didactic Game, CEK.

\section{INTRODUÇÃO}

O ensino de química nas aulas do Ensino Médio, na maioria das vezes, apresenta uma abordagem completamente tradicional, na qual a maior preocupação é a memorização e reprodução do conhecimento por parte dos estudantes. No ensino tradicional, o professor detentor dos conteúdos, faz uso de recursos didáticos apenas para suas aulas expositivas, utilizando o quadro, pincel e/ou livro didático, o que na maioria das vezes acaba contribuindo para os grandes índices de dificuldades apresentadas pelos estudantes no processo de compreensão de certos conteúdo, disseminando assim, a ideia de que a disciplina de química é uma das mais difíceis e chatas de aprender. Além disso, Mortimer et al. (2000) acabaram observando que os currículos tradicionais têm enfatizado apenas aspectos conceituais da Química, transformando a cultura química escolar em algo completamente descolado de suas origens científicas e de qualquer contexto social do estudante.

Nesta perspectiva, nas últimas décadas, tem-se dado ênfase à educação em química, na qual diversas estratégias e propostas têm sido discutidas e analisadas do ponto de vista da Didática das Ciências (CAMPANARIO; MOYA, 2001; GIL-PEREZ, 1993; GALIAZZI, 2001; et al.). Dentre as atividades apresentadas na literatura, observamos um grande destaque para a utilização de experimentos e até mesmo jogos didáticos no ambiente escolar, viabilizando uma prática docente mais dinâmica e atrativa que incentive o interesse dos estudantes para a disciplina.-

Assim, salientamos que a utilização das práticas experimentais são componentes fundamentais para a construção do conhecimento no processo de ensino-aprendizagem em química. Contudo, mesmo a experimentação sempre tendo estado presente no ensino de Química, somente nas últimas décadas despontaram propostas de atividades preocupadas com a formação de conceitos e adequação à realidade do aluno. Estas propostas procuraram contextualizar os conteúdos químicos e suas aplicações tecnológicas nos âmbitos sociais, 
histórico, político e ambiental.

A experimentação no Ensino de Ciências pode ser vista como uma boa estratégia para a criação de problemas relacionados ao dia a dia do aluno, permitindo-lhe, além da contextualização, o estímulo a indagações a respeito da observação (DELORS, 2001). Já as atividades lúdicas na sala de aula, como os jogos didáticos, proporcionam ao estudante uma forma prazerosa e divertida de estudar, além de oferecer ao professor uma maneira diferente de avaliar a construção do conhecimento em relação aos conteúdos estudados, de revisar conteúdo ou como um meio mais dinâmico de fixar o conhecimento, permitindo a identificação de erros de aprendizagem (ZANON et al., 2008).

De acordo com o exposto, o presente trabalho tem por objetivo analisar o desenvolvimento de uma atividade experimental e um jogo didático para o conteúdo de "Tensão superficial", baseado no Ciclo da Experiência Kellyana - CEK.

\section{FUNDAMENTAÇÃO TEÓRICA}

Sabemos que a utilização de experimentação no ensino da química acaba possibilitando diversas habilidades, como construção do conhecimento científico, a contextualização das atividades por meio do emprego de temas geradores, vinculação dos conteúdos com os aspectos sociais, despertando o senso crítico reflexivo dos estudantes e até mesmo o emprego de material simples, de baixo custo e de fácil aquisição. A prática experimental no Ensino de Ciências deve ser realizada considerando que as previsões sejam tão importantes quanto os processos de pensamento usados para desenvolvê-las (WELLS, 1998).

Contudo, também sabemos, que em pleno século XXI, ainda se tem uma grande barreira quando se trata da utilização da experimentação no ensino da química, em que na maioria das vezes os estudantes relatam que não tem aulas experimentais, e que consideram a disciplina chata devido a essas lacunas ainda existentes. Uma das principais características relacionadas ao ensino de Química nos níveis fundamental e médio da educação básica é o desinteresse dos alunos para o estudo desta ciência. Esta falta de interesse decorre, principalmente, da metodologia de ensino tradicionalmente empregada, fundamentada na memorização de conceitos e regras de nomenclatura e na aplicação de fórmulas na resolução de problemas, muitas vezes, diretamente vinculados ao preparo para concursos e vestibulares.

Em consequência, tem-se um ensino que se coloca afastado da realidade do aluno, gerando espaço para um questionamento por parte deste, sobre os reais objetivos do estudo da Química. Para Lima et al. (2000) a contextualização do ensino, aproximando o dia-a-dia dos alunos e o conhecimento científico foi apontada como uma solução para reduzir o alto nível de 
rejeição da Química. Estes autores destacaram a pouca utilização de aulas experimentais, geralmente demonstrativas, que não permitem a participação ativa do aluno ou apenas os convidam a seguir um roteiro, sem levar em consideração o caráter investigativo e a relação entre o experimento e os conceitos.

Além de desmotivar o aluno, não se atinge o objetivo de formar um cidadão crítico, que pode discutir as questões cruciais das quais a Química participa no mundo moderno. Acreditamos assim, como Pozo (1998) que o papel do professor neste processo é de suma importância, pois o mesmo pode auxiliar o estudante na tarefa de formulação e reformulação de conceitos, ativando seus conhecimentos prévios e articulando-os a uma nova informação que está sendo apresentada.

Ao analisar o papel da experimentação na construção do conhecimento científico e sua relevância no processo de ensino-aprendizagem, Giordan (1999) constatou que a experimentação desperta um forte interesse entre os alunos, que atribuem a esta um caráter motivador, lúdico e essencialmente vinculado aos sentidos. As atividades práticas consistiram em um excelente recurso didático para a construção do conhecimento. O emprego desta estratégia favoreceu tanto o caráter investigativo quanto a capacidade de tomada de decisão. Além de colaborarem para a formação do pensamento crítico, estes fatores são fundamentais na construção da cidadania. Segundo Santos e Schnetzler (2000), através da valorização da participação ativa do aluno nas atividades, tem-se o desenvolvimento de duas habilidades básicas na formação da cidadania: a capacidade de participação e de tomada de decisão.

Podemos afirmar então, que a experimentação e jogos didáticos para o processo de ensino e aprendizagem, também auxilia na relação professor e aluno e até mesmo aluno e aluno. O professor deve rever a utilização de propostas pedagógicas passando a adotar em sua prática aquelas que atuem nos componentes internos da aprendizagem, já que estes não podem ser ignorados quando o objetivo é a apropriação de conhecimentos por parte do estudante (KISHIMOTO, 1994). É importante destacar então, que as práticas experimentais e jogos didáticos, se bem utilizadas, vai despertar nos estudantes o senso crítico e reflexivo, e também oportunizar o aperfeiçoamento do seu conhecimento já existente, no qual, Kishimoto (1994), destaca que no momento o estudante encara o jogo como uma brincadeira, aprende o conteúdo sem perceber.

\section{METODOLOGIA}

Esta pesquisa apresenta um caráter qualitativo, que segundo Gil (1999), o uso dessa abordagem propicia o aprofundamento da investigação das questões relacionadas ao fenômeno 
em estudo e das suas relações, mediante a máxima valorização do contato direto com a situação estudada, buscando-se o que era comum, mas permanecendo, entretanto, aberta para perceber a individualidade e os significados múltiplos.

O estudo foi desenvolvido por meio de intervenções do Grupo de Trabalho (GT) de experimentação do Programa Internacional despertando Vocações para as Licenciaturas (PDVL), que tem como principal objetivo promover aos estudantes de escolas públicas do Ensino Médio, parceiras do programa, a oportunidade de enxergar a Química de uma maneira que os aproximem da realidade, através da realização de atividades experimentais no ensino de Química.

O campo da pesquisa foi a EREM Dias Cardoso, localizada na cidade de Vitória de Santo Antão, no interior de Pernambuco e tivemos como sujeitos trinta (30) estudantes da $1^{\text {a }}$ série do Ensino Médio. Nos procedimentos, realizamos um experimento químico intitulado “Tensão Superficial” e um jogo didático de Tiro ao Alvo, relacionado ao conteúdo de Tensão, por meio da base metodológica do Ciclo da Experiência Kellyana (CEK), desenvolvida a partir da Teoria dos Construtos Pessoais de George Kelly (1955).

Kelly (1955) defende que a aprendizagem não é algo especial que acontece apenas nas escolas, ou em algumas ocasiões, mas um processo diretamente ligado à vivência de uma experiência (LIMA, 2008). E essa experiência acontece a partir de um ciclo que apresenta cinco etapas, que estão especificadas abaixo:

- Antecipação: Momento no qual o indivíduo utiliza seus construtos pessoais no seu sistema de construção e tenta antecipar um evento que está prestes a acontecer.

- Investimento: Momento de se preparar para se encontrar com o evento, ou seja, melhorar a construção da réplica através da introdução de novos saberes.

- Encontro: Momento de se deparar com o evento que antecipou.

- Confirmação ou desconfirmação: Momento de confirmar ou desconfirmar suas hipóteses iniciais através da vivência no evento.

- Revisão construtiva: Momento de reconstruir seus construtos.

Abaixo, explicitamos todo o planejamento da intervenção baseado no CEK:

1. Antecipação: Dividimos a turma em grupos e realizamos alguns questionamentos aos estudantes, envolvendo o conteúdo de tensão superficial abordado no experimento. No qual, jogamos um desafio aos estudantes com base experimental do feijão e a água, referentes à $\boldsymbol{P 1} \boldsymbol{e} \boldsymbol{P 2}$. Em um copo de água, fomos adicionando caroços de feijões, até a agua esborrar do copo. As perguntas são mostradas a seguir: 


\section{P1: Quantos feijões cabem no copo com água, sem que a água esborre?}

\section{P2: Por que a água não esborrou?}

P3: $O$ que aconteceria com o leite se fosse adicionado ao detergente?

P4: Por que alguns insetos conseguem andar sob as águas?

\section{P5: O que é tensão superficial?}

2. Investimento: Foi explicado de forma expositiva o conteúdo de tensão superficial, abordando os tópicos das ligações de hidrogênio e esclarecendo que a tensão superficial é um efeito físico que ocorre na interface entre duas fases químicas, fazendo com que a camada superficial de um líquido venha a se comportar como uma membrana elástica. Explicamos também que esta propriedade é causada pelas forças de coesão entre moléculas semelhantes, cuja resultante vetorial é diferente na interface.

3. Encontro: Foi realizado o experimento de tensão superficial do leite, utilizando apenas materiais de baixos custos. Ainda em grupos, a atividade experimental se decorreu em equipe, seguido o roteiro abaixo:

- Em um prato descartável, adicionar um pouco de leite;

- Em seguida, adicionar corante ao leite e apenas aguardar espalhar;

- Pegar palitos de churrascos e adicionar na ponta um pouco de detergente;

- Por fim, com os palitos com detergente, introduzir ao leite com corante.

4. Confirmação desconfirmação: Realizamos novamente questionamentos acerca do conteúdo do experimento. As perguntas se assemelham as questões da antecipação, como podemos observar abaixo:

\section{P1: Quantos feijões cabem no copo com água, sem que a água esborre?}

\section{P2: Por que a água não esborrou?}

\section{P3: O que ocorreu com o leite?}

P4: Por que alguns insetos conseguem andar sob as águas?

\section{P5: O que é tensão superficial?}

Neste momento os estudantes construíram ou reconstruíram seus conhecimentos prévios acerca do conteúdo. Aplicamos em seguida um jogo didático de tiro ao alvo, no qual cada grupo teve a oportunidade de possuir 4 dardos, ou seja, 4 jogadas. No alvo existiam pontuações positivas $+50,+40,+30$ e +20 e negativas $-40,-30,-20$ e -10 , onde cada grupo por vez, lançava um dardo, caso acertassem ou não as pontuações, os estudantes deveriam responder as questões referentes a antecipação, na qual a pontuação positiva só seria considerada caso acertada a 
resposta. Quanto mais pontuações positivas acertadas, maiores as chances de ganhar. Por fim, as pontuações eram anotadas conforme eram respondidas as questões, porém, só foram consideradas no final da atividade, pois ocorreu uma correção das respostas com a turma.

5. Revisão construtiva: Foi pedido que os estudantes relatassem sobre a experiência vivida em sala de aula, se gostaram da metodologia utilizada, se conseguiram compreender o conteúdo e associar ao seu cotidiano, e a importância das aulas experimentais nas aulas de química, e também, a realização de uma auto avaliação sobre todo o processo.

Imagem 1: Atividades realizadas com base no CEK. Fonte: Própria

\section{RESULTADOS E DISCUSSÃO}

$\mathrm{Na}$ antecipação, recolhemos as respostas dos estudantes nos questionamentos realizados. Abaixo, mostramos as respostas de todos os grupos (Tabela 1). Observamos que nesta primeira etapa, alguns grupos conseguiram responder, tendo conhecimentos prévios consistentes no conteúdo abordado, mas, alguns grupos, demonstraram confusão no conteúdo, inclusive, quando atrelado ao cotidiano, evidenciando o conhecimento escasso acerca da temática.

Tabela 1: Resolução dos estudantes nos questionamentos realizados na antecipação. Fonte: Própria

\begin{tabular}{|c|c|c|c|c|c|}
\hline & G1 & G2 & G3 & G4 & G5 \\
\hline P1 & 8 & 20 & 5 & 10 & 20 \\
\hline P2 & $\begin{array}{l}\text { Por conta da } \\
\text { densidade de cada } \\
\text { feijão, menos } \\
\text { densidade }\end{array}$ & $\begin{array}{ll}\text { Por que } & \text { o } \\
\text { feijão } & \text { é } \\
\text { pequeno } & \text { e } \\
\text { leve. } & \end{array}$ & $\begin{array}{l}\text { Por que o corpo } \\
\text { está cheio e o } \\
\text { feijão só pode } \\
\text { inchar depois } \\
\text { de muito tempo }\end{array}$ & $\begin{array}{l}\text { Por que essa } \\
\text { quantidade } \\
\text { tem uma } \\
\text { densidade } \\
\text { regular para a } \\
\text { água não } \\
\text { derramar. }\end{array}$ & $\begin{array}{lr}\text { Por que } & \text { o } \\
\text { feijão afunda } \\
\text { e não faz } \\
\text { volume no } \\
\text { fundo } \\
\text { copo. }\end{array}$ \\
\hline P3 & $\begin{array}{l}\text { Como leite apolar } \\
\text { ele dissolve o } \\
\text { corante que } \\
\text { também é polar } \\
\text { "Semelhante } \\
\text { dissolve } \\
\text { semelhante" }\end{array}$ & $\begin{array}{l}\text { Quando } \\
\text { colocar } \\
\text { corante ao } \\
\text { leite, e colocou } \\
\text { o detergente a } \\
\text { película se } \\
\text { rompeu. }\end{array}$ & $\begin{array}{l}\text { Aconteceu uma } \\
\text { reação quando a } \\
\text { gente misturou } \\
\text { o corante e } \\
\text { transformou e } \\
\text { uma barreira, e } \\
\text { quando colocou } \\
\text { detergente a } \\
\text { barreira } \\
\text { quebrou. }\end{array}$ & $\begin{array}{l}\text { O detergente } \\
\text { quebra as } \\
\text { partículas de } \\
\text { gorduras do } \\
\text { leite. }\end{array}$ & $\begin{array}{l}\text { Ela mudou } \\
\text { de coloração. }\end{array}$ \\
\hline
\end{tabular}




\begin{tabular}{|c|c|c|c|c|c|}
\hline P4 & $\begin{array}{l}\text { Tensão superficial } \\
\text { é um efeito físico } \\
\text { que ocorre entre } \\
\text { duas } \\
\text { químicas. }\end{array}$ & $\begin{array}{l}\text { Por conta da } \\
\text { camada } \\
\text { protetora e } \\
\text { também temos } \\
\text { que ter } \\
\text { cuidado para } \\
\text { não esborrar. }\end{array}$ & $\begin{array}{l}\text { Por causa da } \\
\text { tensão } \\
\text { superficial. }\end{array}$ & $\begin{array}{l}\text { Por causa da } \\
\text { tensão } \\
\text { superficial. }\end{array}$ & $\begin{array}{l}\text { Tensão } \\
\text { superficial }\end{array}$ \\
\hline P5 & $\begin{array}{l}\text { Uma película que } \\
\text { fica sobre a água. }\end{array}$ & $\begin{array}{l}\text { Formação de } \\
\text { película. }\end{array}$ & $\begin{array}{l}\text { Uma película } \\
\text { que formou } \\
\text { sobre a água. }\end{array}$ & $\begin{array}{l}\text { É uma ação } \\
\text { que ocorre } \\
\text { dentro da } \\
\text { água, a água } \\
\text { se eleva para } \\
\text { cima } \\
\text { formando } \\
\text { uma película } \\
\text { na superfície. }\end{array}$ & $\begin{array}{lr}\text { A película } \\
\text { que faz a } \\
\text { água não } \\
\text { esborrar. }\end{array}$ \\
\hline
\end{tabular}

No investimento, com o esclarecimento dos tópicos do conteúdo de acordo com as dificuldades dos estudantes observadas na antecipação, observamos que os mesmos foram participativos e estavam sempre interagindo e sanando dúvidas.

No encontro, momento que foi realizado as atividades experimentais (Figura 1), com o experimento do leite, os estudantes foram ativos na atividade, sempre participando e levantando hipóteses com base nas explicações dadas na etapa anterior.

Figura 1: Atividades realizadas com base no CEK. Fonte: Própria 


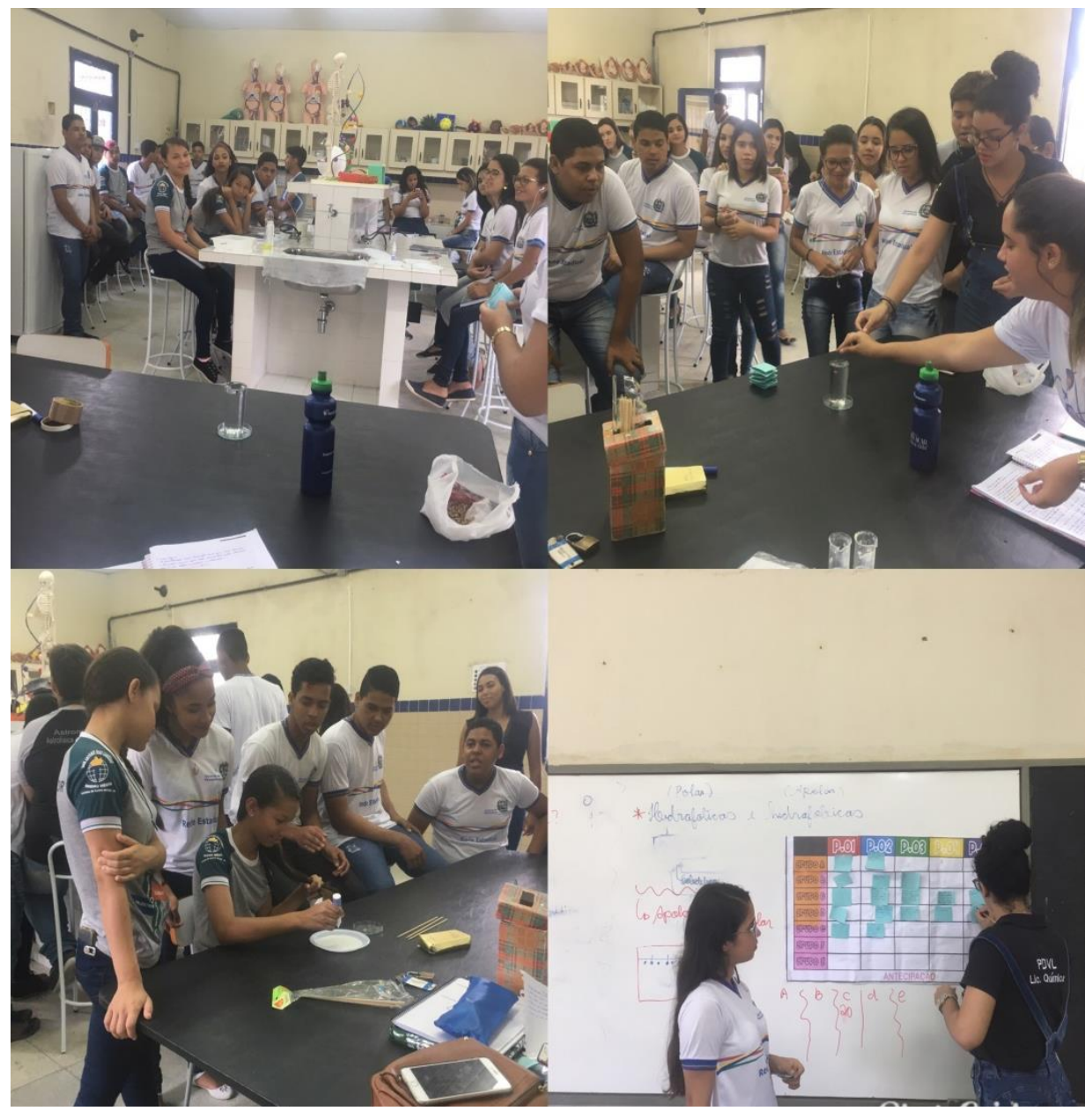

$\mathrm{Na}$ etapa da confirmação $\boldsymbol{e}$ desconfirmação, alguns grupos reconstruíram seus conhecimentos prévios, lapidando suas respostas. Na tabela 2, apontamos as resoluções dos grupos nos questionamentos realizados.

Tabela 2: Resolução dos estudantes nos questionamentos realizados na confirmação e desconfirmação. Fonte:

\begin{tabular}{|l|l|l|l|l|l|}
\hline & G1 & G2 & G3 & G4 & G5 \\
\hline P1 & 60 & 60 & 60 & 60 & 60 \\
\hline P2 & $\begin{array}{l}\text { Por causa da tensão } \\
\text { superficial, } \\
\text { formando uma por que } \\
\text { película. }\end{array}$ & $\begin{array}{l}\text { Foi parte de } \\
\text { formou uma } \\
\text { película em } \\
\text { cima do copo, } \\
\text { por causa da } \\
\text { cimana não tem } \\
\text { uma }\end{array}$ & $\begin{array}{l}\text { Por causa da } \\
\text { tensão } \\
\text { superficial. } \\
\text { comoressão na parte } \\
\text { de baixo. }\end{array}$ & $\begin{array}{l}\text { Em cima } \\
\text { formou uma } \\
\text { película, por } \\
\text { que não tinha } \\
\text { compressão } \\
\text { na parte de } \\
\text { cima }\end{array}$ \\
\hline
\end{tabular}




\begin{tabular}{|c|c|c|c|c|c|}
\hline P3 & $\begin{array}{l}\text { Com o leite apolar } \\
\text { ele dissolve o } \\
\text { corante que também } \\
\text { é polar "Semelhante } \\
\text { dissolve } \\
\text { semelhante" }\end{array}$ & $\begin{array}{l}\text { Quando } \\
\text { colocar corante } \\
\text { ao leite, e } \\
\text { colocou r o } \\
\text { detergente } \\
\text { película } \\
\text { rompeu. }\end{array}$ & $\begin{array}{l}\text { Houve a quebra } \\
\text { das moléculas } \\
\text { de gorduras } \\
\text { existentes no } \\
\text { leite. }\end{array}$ & $\begin{array}{l}\text { As ligações } \\
\text { foram } \\
\text { quebradas } \\
\text { com o } \\
\text { detergente. }\end{array}$ & $\begin{array}{l}\text { Quebra das } \\
\text { ligações de } \\
\text { gordura que } \\
\text { tem no leite. }\end{array}$ \\
\hline P4 & $\begin{array}{l}\text { Por causa da } \\
\text { membrana que é } \\
\text { formada devido a } \\
\text { tensão }\end{array}$ & $\begin{array}{l}\text { Por meio da } \\
\text { tensão } \\
\text { superficial, } \\
\text { com as ligações } \\
\text { formando uma } \\
\text { membrana. }\end{array}$ & $\begin{array}{l}\text { Por causa da } \\
\text { tensão } \\
\text { superficial. }\end{array}$ & $\begin{array}{l}\text { Devido as } \\
\text { ligações que } \\
\text { ocorrem na } \\
\text { parte de cima } \\
\text { da água, } \\
\text { formando } \\
\text { uma } \\
\text { membrana }\end{array}$ & $\begin{array}{l}\text { Por causa da } \\
\text { tensão, que } \\
\text { forma uma } \\
\text { membrana. }\end{array}$ \\
\hline P5 & $\begin{array}{l}\text { Uma película que } \\
\text { fica sobre a água } \\
\text { devido a algumas } \\
\text { ligações químicas } \\
\text { existentes. }\end{array}$ & $\begin{array}{l}\text { Formação de } \\
\text { película devido } \\
\text { as ligações de } \\
\text { H. }\end{array}$ & $\begin{array}{l}\text { Uma película } \\
\text { que formou } \\
\text { sobre a água, } \\
\text { por causa de } \\
\text { ligações que se } \\
\text { formam de } \\
\text { maneiras } \\
\text { diferentes. }\end{array}$ & $\begin{array}{l}\text { Como tem } \\
\text { ligações que } \\
\text { na parte de } \\
\text { cima não } \\
\text { sofrem } \\
\text { compressão, } \\
\text { acaba } \\
\text { formando } \\
\text { essa película } \\
\text { chama de } \\
\text { tensão } \\
\text { superficial. }\end{array}$ & $\begin{array}{l}\text { Membrana } \\
\text { formada } \\
\text { devido } \\
\text { algumas } \\
\text { ligações. }\end{array}$ \\
\hline
\end{tabular}

Tratando da confirmação e desconfirmação, pode-se perceber que alguns grupos permaneceram com os mesmos pensamentos em algumas respostas, já outros, reconstruíram seus conhecimentos, identificando os fenômenos ocorridos nos experimentos e conseguindo associar ao seu cotidiano.

Com o jogo didático "Tiro ao alvo", percebemos que o ambiente tornou-se mais dinâmico, incentivando os estudantes a maior participação, aproximando os mesmos ao conteúdo por meio das perguntas no jogo. Apontamos o grupo 3 como vencedor, considerando os acertos com os dardos no alvo, mas destacamos que todos os grupos conseguiram responder todas as perguntas, evidenciando uma vez mais a construção de conhecimentos no conteúdo.

$\mathrm{Na}$ última etapa, revisão construtiva, por meio de um debate, os estudantes relataram a grande contribuição da atividade experimental, relatando também que não acharia necessárias alterações na metodologia utilizada. Declarando que conseguiram compreender o conteúdo e associar com o seu cotidiano, compreendendo o fenômeno do detergente no momento que se é 
lavado um prato na sua casa. Tratando do auto avaliação de todo o processo, os estudantes relataram que deveriam ter mais aulas experimentais e lúdicas, avaliando seus desempenhos como bem melhores do que nas aulas cotidianas e definiram a atividade realizada como espetacular, deste modo, conseguindo compreender o conteúdo.

\section{CONCLUSÕES}

Diante do exposto, é possível afirmar o quanto as aulas experimentais aliadas ao CEK tem uma influência satisfatória no processo de ensino e aprendizagem, em que os estudantes também passaram a ver a química de uma forma diferente daquela ideia de química difícil, chata e com aulas apenas expositivas e extremamente tradicionais.

Com a realização das atividades experimentais e lúdicas, permitimos a disseminação de novas propostas para o ensino de química, que além da contribuição para a perspectiva da aprendizagem, proporciona-se também uma prática que possibilita ao professor momentos para repensar sobre as aulas que estão sendo ministradas nas escolas na disciplina de química, principalmente aquelas ministradas por profissionais que não têm formação na área. Sendo assim, uma educação química mais dinâmica e em conjunto com as aulas práticas experimentais e lúdicas pode facilitar a aprendizagem do aluno e até envolver o professor de forma com que ele busque sempre a inovação das suas aulas conseguindo quebrar os paradigmas de que a química é desagradável.

\section{REFERÊNCIAS}

CAMPANARIO, J. M.; MOYA, A. ¿Como enseñar ciencias? principales tendencia y propuestas. Enseñanza de las Ciencias, n. 17, v. 2, 2001. p. 179-192.

DELORS, J. Educação: um Tesouro a Descobrir. 1ª Ed. São Paulo: Cortez, 2001.

GALLIAZZI, M. C. et al. Objetivos das atividades experimentais no ensino médio: a pesquisa coletiva como formação de professores de ciências. Ciência e Educação. v.7.n. 2. 2001. p. 249-263.

GIL, A. C. Métodos e técnicas de pesquisa social. 5.ed. São Paulo: Atlas, 1999.

GIL-PEREZ, D. Contribuición de la Historia y de la filosofía de las Ciencias al desarollo de un modelo de enseñanza e aprendizaje como investigación. Enseñanza de las Ciencias. v. 11, n. 2, 1993. p. 197-212.

GIORDAN, M. O Papel da Experimentação no Ensino de Ciências. Química Nova na Escola, 1999. 
KELLY, G. A. A theory of personality: the psychology of personal constructs. New York: W. W. Norton, 1963.

KISHIMOTO, Tizuko Morchida. O jogo e a educação infantil. $1^{\text {a }}$ ed. São Paulo: Pioneira, 1994.

LIMA, J. F. L.; et al. A contextualização no ensino de cinética química, Química Nova na Escola. 11, 26-29, 2000.

MORTIMER, E. F.; MACHADO, A. H.; ROMANELLI, L. I. A proposta curricular de Química do estado de Minas Gerais: fundamentos e pressupostos. Química Nova, v. 23, n. 2,2000 .

POZO, J. I. Teorias Cognitivas da Aprendizagem. $3^{\text {a }}$ ed. Tradução de J. A. Llorens. Porto Alegre: Artmed, 1998. 284p.

SANTOS, W. L. P.; SCHNETZLER, R. P. Educação em Química: compromisso com a cidadania. $2^{a}$ Ed., Ijuí, Editora Unijuí, 2000.

WELlington, J. (ed.) Practical Work in School Science. London: Routledge. 1998.

ZANON, D.A.V.; GUERREIRO, M.A.S.; OLIVEIRA, R.S. Jogo didático Ludo Químico para o ensino dos compostos orgânicos: projeto, produção, aplicação e avaliação. Ciência e Cognição. v. 13, 2008. p. 72-81. 